\title{
A pessoa com deficiência em Maringá-PR e seu ingresso no mercado de trabalho
}

Vânia de Menezes ${ }^{1}$

Resumo: As deficiências podem ser conceituadas num contínuo de dificuldades menores de funcionalidade a grandes impactos sobre a vida de uma pessoa. Evidências sólidas dentro de uma realidade marcada por distorções sociais são imperiosa a adoção de políticas públicas voltadas à inclusão social. Nesse contexto, é de extrema importância para compreensão e garantia da estabilidade destes, uma análise da fiscalização nas empresas públicas e privadas maringaenses no cumprimento do art. 93 da Lei no 8.213, de 24 de julho de 1991.

Palavras-chave: Pessoa com deficiência, Inclusão, Mercado de trabalho maringaense, Fiscalização maringaense.

Abstract: Deficiencies can be conceptualized in a continuum of minor difficulties in workity to large impacts on a person's life. Solid evidence within a reality marked by social distortions are overriding the adoption of targeted social inclusion policies. In this context, it is of utmost importance for understanding and ensuring the stability of such an

${ }^{1}$ Licenciada e bacharel em ciências sociais (2009) pela Universidade Estadual de Maringá (UEM). Professora Especialista em Docência do Ensino Superior (2012) pela Faculdade de Tecnologia América do Sul. Professora Especialista em Educação do/no Campo (2013) pela Faculdade Eficaz e Professora Especialista em Educação Especial (2013) pela Faculdade de Tecnologia América do Sul. Atualmente tem experiência na área de educação, com ênfase em sociologia, antropologia e ciências política, atuando como docente pela Secretaria Estadual de Educação do Estado do Paraná-SEED-PR (2010). Residente no município de Maringá-PR/BR. E-mail: vaniarpm @ yahoo.com.br 
analysis of surveillance in public companies Maringá private and in fulfilling art. 93 of Law No. 8,213, of July 24, 1991.

Keywords: Person with disability, Inclusion maringaense, Labour market maringaense .. Surveillance maringaense.

\section{Introdução}

A deficiência é complexa, dinâmica, multidimensional, e questionada. Os conceitos foram evoluindo conforme as crenças, valores culturais, concepção de homem e transformações sociais que aconteceram ao longo dos anos. A implementação de políticas públicas voltadas para a inclusão têm por finalidade sanar uma divida histórica com relação à exclusão destes em todos os espaços sociais, seja ela saúde, previdência social, empregabilidade, educação, enfim, direitos fundamentais de um cidadão. Neste sentido, as análises empreendidas com relação a estas políticas tornam-se necessárias a partir do momento em que este se torna um direito nos mais diversos espaços do meio social.

Nesse contexto, o trabalho desenvolvido nesta, analisará o artigo 93, da Lei ${ }^{\circ}$ 8.213/91, como garantia da estabilidade destes no mercado de trabalho, como também, a fiscalização nas empresas tanto públicas como privadas maringaenses no cumprimento deste. $\mathrm{O}$ instrumental metodológico e conceitual utilizado pressupõe que a 
sociedade capitalista constrói e reproduz a desigualdade no próprio processo de produção da vida, uma vez que, esta representação permite uma abordagem da hierarquia social constituída pelos agrupamentos convivendo no espaço social em condições de desigualdade, mesmo com as políticas de inclusão.

A metodologia de definição da deficiência (DINIZ, 2007) reflete a diversidade de estilos de vida dos deficientes e a revolução na ideologia opressora do corpo deficiente. Em seguida em complementos desta, (LOBO, 2009), analisa os processos de dominação, disciplinarização e controle dos invisíveis na história brasileira, e por fim a contribuição de (SKLIAR, 2003), com a tese sobre a política e filosofia da diferença e a dialética da inclusão/exclusão.

\section{O "Estranho"}

Quando se fala em pessoas com deficiência, antes é preciso trazer contribuições contemporâneas acerca do tema proposto. Fazendo um resgate histórico de como os mesmos sempre foram tratados até então.

Segundo Diniz (2007), a deficiência passou a ser um conceito político: A expressão da desvantagem social sofrida pelas pessoas com diferentes lesões. E, nesse movimento de redefinição da deficiência, termos como "pessoa portadora de deficiência", "pessoa com 
deficiência", "pessoa com necessidades especiais", e outros agressivos, como "aleijado", "débil-mental", "retardado", "mongolóide", "manco" e "coxo" foram colocados na mesa de discussões. Exceto pelo abandono das expressões mais claramente insultantes, ainda hoje não há consenso sobre quais os melhores termos descritivos.

Recente estudo de (Lobo, 2009) com a tentativa de compreender as marcas deixadas no corpo social pelos 350 anos de escravidão e as influências destas na construção dos eixos de formação dos padrões de normalidade. Para ela, o Índico representava o caminho do exotismo, no qual habitavam monstros fabulosos criados a partir de relatos que sempre misturavam descrições do que presenciavam e maravilhas que ouviam dizer. Nota-se aqui, que a cientista busca refletir a visão etnocêntrica ${ }^{2}$ dos Europeus com relação aos índios: Monstros canibais no "descobrimento" do Brasil e ainda observa que se a Idade Média e o Renascimento inventaram monstros nas artes, nas descrições e nos relatos dos viajantes, o século XIX passou a fabricá-los em carne e osso (p.46): nascia então a teratogenia ${ }^{3}$.

É preciso considerar que houve um intenso processo de urbanização do Brasil, que levou como princípio a reprodução destas

\footnotetext{
${ }^{2}$ Visão Etnocêntrica: Demonstra, por vezes, desconhecimento dos diferentes hábitos culturais, levando ao desrespeito, depreciação e intolerância por quem é diferente, originando em seus casos mais extremos, atitudes preconceituosas, radicais e xenófobas.

${ }^{3}$ Teratogenia: produção e desenvolvimento de anomalias.
} 
diferenças. A criação do "outro", como é enfatizado também por (SKLIAR, 2003), tem uma forte associação com o mal:

É o outro do mal e a própria origem do mal: A explicação de todo conflito, a mesma negatividade da cultura; o outro é, em síntese, aquele espaço que não somos, que não desejamos ser, que nunca fomos e nunca seremos. O outro está maleficamente fora de nós mesmos (SKLIAR, 2003, p. 117).

Podemos afirmar que os sujeitos falam tanto do outro (do pobre), pois assim o outro que aparece é um outro construído pela identidade e, nesse sentido, é a mesmidade se reproduzindo (SKLIAR, 2003, p. 109). Assim, o que está em jogo é o controle e o exercício de poder sobre o outro. (SKLIAR, 2003, p. 114).

\section{Previsões legais: inclusão e mercado de trabalho, teoria vs prática.}

O processo de integração da pessoa com deficiência na sociedade brasileira ocorre de forma lenta e através de um padrão de normalidade estabelecido pela sociedade que considera o trabalho como atividade fundamental para que este seja plenamente inserido na sociedade. Desta forma, a proteção destes passou a integrar as normas constitucionais brasileiras recentemente. A partir da Constituição Federal de 1988, graças à pressão social, criaram-se dispositivos legais 
em áreas como educação, trabalho, assistência social e acessibilidade física, para garantir a sua inclusão social.

O artigo $^{\circ}$ da Constituição Federal de 1988 estabelece os princípios de soberania, de cidadania, a dignidade da pessoa humana, os valores sociais do trabalho e da livre iniciativa, o pluralismo político e indica, em seu artigo $3^{\circ}$, os objetivos voltados para a construção de uma sociedade livre, justa e solidária, a garantia do desenvolvimento nacional, a erradicação da pobreza e da marginalização, a redução das desigualdades sociais e regionais e a promoção do bem de todos, sem preconceitos de origem, raça, sexo, cor, idade e quaisquer outras formas de discriminação.

A Lei $\mathrm{n}^{\circ} 7.853$, de 24 de outubro de 1989, dispõe sobre o apoio às pessoas com deficiência e cria a Coordenadoria Nacional para Integração da Pessoa Portadora de Deficiência (CORDE), diretamente ligada á Secretaria de Estado dos Direitos Humanos, ao Conselho Nacional dos Direitos da Pessoa Portadora de Deficiência (CONADE) órgão superior de deliberação colegiada integrante do Ministério da Justiça, para cuidar dos interesses das pessoas com deficiência, assegura em seu Art. $2^{\circ}$, inciso III, às pessoas com deficiência os direitos na área da formação profissional e do trabalho.

Todavia, as dificuldades das pessoas com deficiência não está em encontrar vagas de trabalho, mas na falta de qualificação para garantir sua inclusão e permanência neste mercado, além dos 
critérios apresentados pelo empregador que não prepara espaço físico para receber a pessoa com deficiência, além de escolher o tipo de deficiência permitida para contratação a fim de evitar despesas e facilitar a convivência.

De acordo com o IBGE (2010), pessoas com deficiência representam $24 \%$ da população brasileira. A constatação faz parte do Censo Demográfico 2010 - Características Gerais da População, Religião e Pessoas com Deficiência, divulgado em 29/06/2012, pelo Instituto Brasileiro de Geografia e Estatística (IBGE).

O levantamento aponta ainda que, em 2010, a população ocupada com pelo uma das deficiências investigadas representava 23,6\% (20,3 milhões) do total ocupado (86,3 milhões) no país. Além disso, mais da metade (53,8\%) dos 44 milhões de pessoas com deficiência em idade ativa (10 anos ou mais) estava desocupada ou não era economicamente ativa. Sabemos que, para que haja uma superação com relação à exclusão destes, é preciso que as mesmas tenham acesso ao mercado de trabalho ou a meios de subsistência, que elimine o vínculo entre deficiência e pobreza.

Entre as conquistas como matéria de ordem pública ${ }^{4}$, o artigo 93, da Lei $n^{\circ} 8.213 / 91$, manifesta ação afirmativa ${ }^{5}$ em favor das pessoas

${ }^{4}$ Ordem Pública: As matérias de ordem pública são aquelas que o Poder Público consagra como de significativa relevância para o Estado, não sendo passível de mitigação por vontade de particular. 
com deficiência. Esta, ao dispor, mormente sobre planos de benefício da previdência social, incluiu em seu texto disposição atinente à inserção e manutenção de empregados portadores de deficiência no mercado de trabalho. No âmbito de aplicação, a legislação estabeleceu a obrigatoriedade das empresas com cem (100) ou mais empregados preencherem uma parcela de seus cargos com pessoas com deficiência.

A reserva legal de cargos também conhecida como Lei de Cotas e para a conservação deste percentual, na perspectiva de manter uma regularidade no número de pessoas com deficiência nos postos destinados à política de cotas exarada pelo artigo 93 em estudo, o legislador ordinário previu preceito cogente. Dessa forma, enquanto perdurar a atividade empresarial, o número total de reabilitados ou de pessoas com deficiência habilitadas deve respeitar o percentual indicado pela norma em estudo. Portanto, em resposta à saída de um deles, exigese, a rigor, a contratação prévia de outra pessoa que se adeqúe ao perfil trazido pelo artigo 93, da lei em vigor.

No Estado do Paraná, a lei que estabelece cotas de ocupação já existe há 23 anos, e segundo um levantamento feito pela Secretaria de Estado do Trabalho e Promoção Social (SETP), a contratação destes

\footnotetext{
${ }^{5}$ Manifestação afirmativa: Ações afirmativas é a expressão utilizada para se referir a políticas públicas que visam assegurar o reingresso social de pessoas que coibidas à marginalização ao longo da história, estão submetidas a uma realidade de exclusão. As suas práticas consistem em ofertar um tratamento de privilégios àqueles socialmente segregados, revertendo uma realidade de privações pelo qual são forçosos a aceitar.
} 
durante os seis primeiros meses de 2010, divulgou que com carteira assinada foram 1.073 pessoas com algum tipo de deficiência no Paraná e que ao longo de 2009, esse número alcançou 2.134 registros. Os números podem parecer altos, mas seriam maiores se as empresas brasileiras respeitassem o artigo 93 da lei 8.213, que estabelece a porcentagem de pessoas com deficiência que deveriam ser contratadas de acordo com o porte de cada empresa.

Junior (2004) afirma que o processo de inclusão está intimamente ligado à Política Nacional de Integração Social das Pessoas com deficiência, sendo a educação objeto tanto da Lei $\mathrm{n}^{\mathrm{o}} 7.853 / 89$, quanto do Decreto $\mathrm{n}^{\circ} 3.298 / 99$ que regulamenta o ensino profissionalizante para a pessoa com deficiência, entendo-se por habilitação profissional o processo destinado a propiciar a pessoa com deficiência, em nível formal e sistematizado, aquisição de conhecimentos e habilidades especificamente associados à determinada profissão ou ocupação, sendo oferecida no nível básico, técnico e tecnólogo, em escola regular, instituições especializadas e nos ambientes de trabalho.

Como se vê, a legislação em nosso país apresenta grandes avanços, mas ao analisar os dados acima, ficam evidentes suas falhas e o enorme caminho para percorrer. 


\section{A reprodução das práticas: a pessoa com deficiência em maringá- pr e seu ingresso no mercado de trabalho}

Como afirma Skliar (2003):

"Fazer do outro um outro parecido, mas um outro parecido nunca idêntico ao mesmo. Não pode ser idêntico pois não seria possível justificar sua posição de "problema", porém deve ser parecido para que possa ser (re-)significado conforme os interesses que estão em jogo." " (SKLIAR, 2003, p. 116)

A sociedade inclusiva que almejamos deve pautar-se na compreensão do significado do termo "inclusão". Para que haja esta mudança é preciso rever valores, adotar práticas de um novo modelo que deve ser construído a partir de reflexões que valorize e respeite as diferenças.

O controle social das políticas públicas para as pessoas com deficiência realiza-se tanto pelos Conselhos como por meio de diversas entidades da sociedade civil envolvidas com o tema. A luta pela implementação dos Conselhos de Pessoas com Deficiência foi possível graças à mobilização e organização das pessoas com deficiência que passaram a falar por si mesmas.

Retomando as previsões legais, a chamada Lei das Cotas, prevê que empresas com mais de 100 funcionários devem 
obrigatoriamente separar de $2 \%$ a $5 \%$ de suas vagas para serem ocupadas por pessoas com deficiência, ou seja, empresas com cem ou mais empregados têm a obrigatoriedade de preencher uma parcela de seus cargos com pessoas com deficiência. Desta forma, a equipe de Recursos Humanos e os gestores das empresas precisam ter clareza que as exigências a serem feitas devem estar adequadas às limitações que as deficiências trazem, lembrando que com as devidas condições garantidas, pois, os trabalhadores com deficiência possuem os mesmos deveres que qualquer outro trabalhador.

$\mathrm{Na}$ agência do trabalhador de Maringá no Paraná, assim como as demais regiões do país, segue as instruções do programa nacional de inclusão oferecendo cursos às pessoas com deficiência cadastradas e da o suporte as empresas para que a inclusão de fato aconteça.

O Programa de Inclusão no município foi criado em 2004 e desde então é coordenado por Ana Carmen Dias.

De acordo com este, as empresas que têm vagas em aberto para deficientes são contactadas para agendamento das entrevistas com os candidatos pré-selecionados pelos responsáveis do programa, e fica como responsabilidade das empresas verificarem as condições de trabalho dos mesmos. Um meio adotado para que estas cumpram a lei, tem sido a assinatura do Termo de Ajustamento de Conduta (TACs), um documento firmado entre as empresas e o Ministério Público do Trabalho, onde essas se comprometem a dar efetiva aplicabilidade à lei. 
O Termo tem eficácia de título executivo extrajudicial, podendo ser executado.

Dados de 2004 até 2007- Após um levantamento de informações por meio de sites e revistas eletrônicas, são percebíveis que o Programa de Inclusão de Pessoas com Deficiência da Agência do Trabalhador de Maringá-PR, desde sua implantação no ano de 2004, até o ano de 2007, passou por vários processos de organizações tais como: Cadastramento destes, levantamento de dados das empresas e seu porte de funcionários, estudos de leis, organizações de palestras, seminários, conferências, entre outras atividades conscientizadoras, entre outras. De acordo com as informações retiradas da revista eletrônica da Associação Comercial de Maringá (ACIM), de setembro de 2011, o programa esta funcionando, mas aponta inúmeras dificuldades, como: O número de cadastro é baixo considerando o número de pessoas com deficiência no município, o não cumprimento da Lei $\mathrm{n}^{\circ}$ 8.213/91 pelas empresas, a falta de adaptação dos ambientes de trabalho visando à inclusão, como também, a falta de estabilidade prevista na legislação trabalhista, entre outras dificuldades aqui não mencionadas.

Dados de 2008, de acordo com o Portal da CidadeMaringá.com, o programa de inclusão da pessoa com deficiência ao mercado trabalho da Agência do Trabalhador dispusera em seu cadastro mais 65 vagas para esse público. Maringá ficou como a segunda cidade do Estado em número de encaminhamentos de pessoas com deficiência 
ao mercado de trabalho, ficando atrás apenas de Curitiba. A coordenadora do programa, Ana Carmem Dias, explica que este número poderia ser mais alto e faz uma reflexão sobre a importância da atualização do cadastro feita pelos mesmos na Agência.

Dados de 2009, após um levantamento de dados na Agência do Trabalhador de Maringá, relacionado à inclusão, divulgada pelo site da Prefeitura Municipal em julho de 2009, o setor ofereceu 206 vagas de empregos e preencheu 118 destes postos, pois, o programa tem por objetivo, criar condições para promover a autonomia, inclusão social e participação efetiva do deficiente na sociedade, mas para participar é preciso que a pessoa com deficiência se cadastre no programa, procurando a coordenadora deste na Agência do Trabalhador.

Dados de 2010, segundo o levantamento divulgado no Jornal do Povo-online em janeiro de 2010, a Agência do Trabalhador está disponibilizando 35 vagas para portadores de necessidades especiais, a responsável pelo programa de inclusão de pessoas com deficiência no trabalho da Agência do Trabalhador de Maringá, Ana Carmem Dias, explica que "as pessoas fazem o cadastro e nós entramos em contato com as empresas que estão com vagas disponíveis" e "uma equipe na agência se responsabiliza pela pré-seleção, buscando recrutar pessoas que a deficiência não interfira na ocupação da vaga".

Dados de 2011, em setembro de 2011, o site da Prefeitura Municipal de Maringá, divulgou uma nota sobre a capacitação de 
funcionários e assistentes sociais do município, que contou com a participação da coordenadora do Programa de Pessoas com Deficiência da Agência do Trabalhador, Ana Carmem Dias, que expôs o dia a dia de seu trabalho e divulgou que há mais de 60 vagas disponíveis e reforça a conscientização sobre a importância do cadastro no programa e atualização do mesmo procurando a Agência.

Dados de 2012, novamente os dados levantados e divulgados no jornal online Odiario.com em agosto de 2012, nos faz refletir, nas principais dificuldades enfrentadas na execução do programa de inclusão da pessoa com deficiência no mercado de trabalho na região de Maringá, o mesmo informa que, a Agência do Trabalhador de Maringá enfrenta dificuldades para preencher as diversas vagas oferecidas para pessoas com deficiência física. $\mathrm{O}$ motivo é a falta de acessibilidade em muitas das empresas para receber essas pessoas, com lugares adequados e formas de trabalho que se adaptem à deficiência de cada um. Além disso, a falta de experiência e qualificação dos próprios portadores de deficiência também dificulta o preenchimento das vagas. Segundo dados do IBGE, o número de deficientes físicos em Maringá passa de 67 mil pessoas, um número grande comparado com as 56 vagas disponibilizadas na Agência do Trabalhador. As vagas são para funções compatíveis às limitações físicas dos deficientes. $O$ que falta, no entanto, é gente para assumir essas vagas. "Ambos os lados tem problema de qualificação. 
Dados de 2013, segundo as informações divulgadas no site pessoa com deficiência (PCD) - Deficiente online, em outubro de 2013, sobram empregos em muitas áreas, mas faltam profissionais capacitados, e mais - histórias de vida mostram que, além da qualificação, falta força de vontade. Alguns desistem de estudar e até de persistir quando se deparam com obstáculos.

Dados de 2014, de acordo com os dados divulgados pelo Odiário.com em abril de 2014, nos últimos dois anos, a Agência do Trabalhador de Maringá registrou a inserção de 330 pessoas com algum tipo de deficiência no mercado, que timidamente vem se abrindo para este público. As dificuldades, contudo, vão além da conscientização de que limitação física não determina potencial, há casos em que a própria pessoa com deficiência se sabota, não participando do programa, e ainda tem a questão da falta de acessibilidade, que não é só rampa, mas toda uma estrutura adequada ao funcionário especial, como a acessibilidade de atitude, de receptividade dos demais funcionários para com aquela pessoa.

\section{Considerações finais}

O "outro", na abordagem antropológica se refere a uma construção identitária, processo pelo qual um grupo constitui um outro grupo de valores, representações e sentidos. 
Avançando cronologicamente na História a tese de Diniz (2007) e (Lobo, 2009) faz sentido, a partir do momento em que notamos que ao longo dos anos, a expressão "o outro" desde o Brasil Colônia, sempre foi utilizada como demarcação de hierarquia e diferenciação social.

Lobo (2009), quando cita em sua obra as expressões "Monstros canibais", o "idiota completo", para relatar a denominação dada pelos portugueses aos povos que aqui viviam na época do "descobrimento" do Brasil, reforça a reprodução da discriminação feita ao longo da história pelas pessoas consideradas "normais" as pessoas com deficiências, como relata Diniz (2007), "aleijado", "débil-mental", "retardado", "mongolóide", "manco" e "coxo".

Diante do exposto, não podemos negar que ao passar dos anos houve uma mudança significativa com relação às políticas públicas voltadas para as pessoas com deficiência no mundo, todavia, as reflexões feitas pelo pesquisador argentino Carlos Skliar (2003) são pertinentes quando afirmar que o percurso que nos espera é extremamente rico e complexo, mas exige um trabalho enorme, já que não nos oferece repousos de tranquilidade.

Ao contar a trajetória da inclusão no mercado de trabalho, a pesquisa aponta para as variadas formas de formação de padrões de normalidade e ainda deixa em evidência que por mais que houve um avanço referente a este no Brasil, no Município de Maringá-PR, o não 
cumprimento da Lei $\mathrm{n}^{\circ}$ 8.213/91 pelas empresas e as inúmeras dificuldades enfrentadas no Programa de Inclusão da Agência do Trabalhador, reforça a ideia de que o programa ainda não atingiu o esperado, por mais que haja um sentimento positivo das pessoas que estão atuando neste, as informações disponibilizadas provam que, as "velhas práticas" embora de forma diferenciada ainda se reproduzam na atualidade, reforçando a pirâmide da divisão social dada pela diferenciação dos indivíduos.

Enfim, diante de todos os dados, é possível concluir que a previsão do artigo 93 da Lei ${ }^{\circ}$ 8.213/91, exige uma revisão precisa, principalmente no que se refere a sua aplicabilidade.

Outro ponto importante a ser analisado aqui, são as práticas voltadas para as políticas públicas de inclusão para as pessoas com deficiência. Estas não podem legitimar as "velhas práticas", as imposições referentes á participação no programa, como também o cumprimento da Lei $\mathrm{n}^{\circ}$ 8.213/91 pelas empresas, não seja o melhor caminho, talvez, um programa de inclusão que tenha como ponto de partida uma parceria entre o setor público e privado, com as empresas, visando à inclusão do mesmo no mercado de trabalho, e o pagamento de um benefício e/ou bolsa, que de assistência a este, antes do término de um curso profissionalizante, seja uma das portas abertas para o sucesso do programa, como também uma adesão positiva do mesmo, pois, a contratação de pessoas com deficiência deve ser planejada para oferecer 
condições ao deficiente e a empresa contratante para manter uma relação saudável no ambiente de trabalho.

Dessa forma este trabalho, nos oferece rico subsídio metodológico para pensar a inclusão e a inserção do mercado de trabalho das pessoas com deficiência, e, os avanços e retrocessos pautados durante a história e o longo caminho ainda a percorrer.

Como sugestão para trabalhos futuros com foco neste assunto, é um estudo voltado para as empresas que cumprem a lei de cotas, um levantamento de dados dos pontos positivos e negativos desta inclusão, como também as dificuldades enfrentadas, e o mais importante, pesquisar qual é o sentimento da pessoa contratada com relação a esta inclusão, esta pesquisa pode servir como parâmetro para a criação de projetos que visem a inserção deste no mercado de trabalho com êxito.

\section{Referências}

ACIM. Associação Comercial e Industrial de Maringá/ Revista eletrônica. Uma jornada para inclusão/ Setembro de 2011. Disponível em: <http://issuu.com/acimvirtual/docs/revista_acim__setembro_de_2011/24>. Acesso em: 15 jul. de 2014.

BOONE, Aline. Sobram vagas de trabalho para deficientes, mas falta acessibilidade e qualificação/ODiario.com/23 Agost. 2012. Disponível em:

<http://blogs.odiario.com/geracaodenoticias/2012/08/23/sobram-vagas-detrabalho-para-deficientes-mas-falta-acessibilidade-e-qualificacao/>. Acesso em: 17 jul. de 2014. 
BRASIL. Decreto Legislativo $n^{\circ} 186$, de 09 de julho de 2008. Aprova o texto da Convenção sobre os Direitos das Pessoas com Deficiência e de seu Protocolo Facultativo, assinados em Nova Iorque, em 30 de março de 2007. Diário Oficial da União de 10.07.2008, republic. em 20.08.2008.

Disponível

em: $<$ http://portal.mec.gov.br/dmdocuments/decreto186.pdf $>$ Acesso em: 04 abr. de 2013.

BRASIL. Instituto Brasileiro de Geografia e Estatística/IBGE. Censo 2010: Número de católicos cai e aumenta o de evangélicos, espíritas e sem religião. Comunicação Social 29 Jun. 2012. Disponível em: < http://censo2010.ibge.gov.br/noticias-

censo ?view $=$ noticia $\& \mathrm{id}=3 \&$ idnoticia $=2170 \&$ busca $=1 \& \mathrm{t}=$ censo $-2010-$ numero-catolicos-cai-aumenta-evangelicos-espiritas-sem-religiao>. Acesso em: 17 jul. de 2014.

BRASIL. Ministério do Trabalho e do Emprego. A inclusão de pessoas com deficiência no mercado de trabalho. 2. ed. Brasília: MTE, SIT, 2007. <http://www.acessibilidade.org.br/cartilha_trabalho.pdf> Acesso em: 8 jan. de 2013, p. 11.

BRASIL. Ministério do Trabalho e do Emprego. A inclusão de pessoas com deficiência no mercado de trabalho. 2. ed. Brasília: MTE, SIT, 2007.

<http://www.acessibilidade.org.br/cartilha_trabalho.pdf> Acesso em: 8 jan. de 2013, p.12.

BRASIL. Ministério do Trabalho e do Emprego. A inclusão de pessoas com deficiência no mercado de trabalho. 2. ed. Brasília: MTE, SIT, 2007. <http://www.acessibilidade.org.br/cartilha_trabalho.pdf> Acesso em: 8 jan. de 2013, p.12-17. 
BRASIL. Ministério do Trabalho e Emprego. A inclusão de pessoas com deficiência no mercado de trabalho. 2. ed. Brasília: MTE, SIT, 2007.

em: <http://www.acessibilidade.org.br/cartilha_trabalho.pdf> Acesso em: 12 jan. de 2013, p.12.

BRASIL. Ministério do Trabalho e Emprego. Instrução Normativa no. 20, de 26 de janeiro de 2001. Dispõe sobre procedimentos a serem adotados pela fiscalização do trabalho no exercício da atividade de fiscalização do trabalho das pessoas portadoras de deficiência. Diário Oficial da União. 29 jan 2001. Disponível em: <http://portal.mte.gov.br/legislacao/instrucao-normativa-n-20-de-26-012001.htm> Acesso em: 12 jan. de 2013.

BRASIL. Lei ${ }^{\circ}$. 12.470, de 31 de agosto de 2011. Diário Oficial da União. Disponível em: <http://www.planalto.gov.br/ccivil_03/_ato20112014/2011/lei/112470.htm> Acesso em: 8 jan. de 2013.

BRASIL. Secretaria de Direitos Humanos da Presidência da República (SDH/PR) / Secretaria Nacional de Promoção dos Direitos da Pessoa com Pessoa com Deficiência (SNPD) - Pessoa com Deficiência Legislação Federal; Brasília: SDH-PR/SNPD, 2012. Disponível em: <http://www.pessoacomdeficiencia.gov.br/app/sites/default/files/public acoes/livro-legislacao-federal-sobre-os-dpd.pdf> Acesso em: 15 jul. de 2014.

BRASIL. Secretaria do Estado do Paraná. Estatuto da Pessoa com Deficiência Minuta de Anteprojeto de Lei de Políticas Públicas do Estado do Paraná, para a promoção e inclusão da Pessoa com Deficiência. $<$ http://www.justica.pr.gov.br/modules/noticias/article.php?storyid=267 \&tit=Consulta-Publica-do-Anteprojeto-de-Lei-do-Estatuto-da-Pessoacom-Deficiencia>. Acesso em: 04 abr. de 2013. 
DINIZ, Débora. O que é deficiência? SP: Brasiliense, 2007. Disponível em: <http://robertagnunes.files.wordpress.com/2011/12/diniz-o-que-edeficiencia-2.pdf>. Acesso em: 12 Jul. 2014.

ESTEVES, Renata da Gama Lima Perez. A "Cota de Deficientes" e os problemas enfrentados quase 20 anos de lei em vigor/ Pires e Gonçalves- Advogados associados/ 06 Dez. 2010. Disponível em: <http://www.pgadvogados.com.br/artigos/mostrar/a_cota_de_deficiente s_e_os_problemas_enfrentados_quase_20_anos_de_lei_em_vigor>.

Acesso em: 18 Jul. 2014.

FURTADO, Thábata. Vagas de emprego para portadores de necessidades especiais/ Jornal do Povo online/ 14 Jan. 2010. Disponível em: <http://www.maringamais.com.br/?pag=noticias_maislidas\&id=4340>. Acesso em: 16 Jul. 2014.

GARCIA, Vera. Empresas ainda discriminam deficientes/Deficiente ciente, o blog da inclusão e cidadania/09 Out. 2010. Disponível em: $<$ http://www.deficienteciente.com.br/2010/08/empresas-aindadiscriminam-deficientes.html>. Acesso em: 16 Jul. 2014.

Aumenta a exclusão de trabalhadores com deficiências nas empresas brasileiras/ Deficiente ciente, o blog da inclusão e cidadania/19 Out. 2010. Disponível em: <http://www.deficienteciente.com.br/2010/08/aumenta-exclusao-detrabalhadores-com.html>. Acesso em: 16 Jul. 2014.

JUNIOR, Roberto Bolonhini. Portadores de necessidades especiais: as principais prerrogativas dos portadores de necessidades especiais e a legislação brasileira. 01. ed. São Paulo: Editora ARX, 2004. v. 01. 381 p.

LOBO, Lilia Ferreira. Os infames da história: pobres, escravos e deficientes no Brasil. SP: Lamparina, 2009. 
MARINGÁ. Agência do Trabalhador. Programa qualifica e encaminha pessoas com deficiência ao mercado de trabalho. 21 jun. 2009. Disponível em: <http://www2.maringa.pr.gov.br/site/index.php?sessao=2f5ac8dd5b552 f\&id=8643> . Acesso em: 16 Jul. 2014.

- Maringá.com/Portal da Cidade. Emprego: Agência do Trabalhador dispõe de vaga para pessoas com deficiência/ 16 Out. 2008. Disponível em: <http://www.maringa.com/noticias/detalhe_noticia.php?not_codigo=59 29>. Acesso em: 16 Jul. 2014.

. Secretaria de Assistência Social e Cidadania. Notícias em Destaque: Funcionários e usuários de serviços assistenciais participam de capacitação/22 Set. 2011. Disponível em: $<$ http://www2.maringa.pr.gov.br/sasc/?cod=noticias/14523>. Acesso em: 16 Jul. 2014.

ONU, Resolução $n^{\circ}$ 2.542/75. Declaração do Direito das Pessoas Portadoras de Deficiência. Disponível em: <http://www.mpdft.gov.br/sicorde/legislacao_01_A1_01.htm> Acesso em: 23 jun. de 2013.

SKLIAR, Carlos. Pedagogia (improvável) da diferença: E se o outro não estivesse aí?/Rio de Janeiro: DP\&A, 2003.

VERZOLA, Ana Luiza. Mercado se abre a pessoas com deficiências/ODiario.com/08 Abr. 2014. Disponível em: <http://m.odiario.com/cidades/noticia/822430/mercado-se-abre-apessoas-com-deficiencias/\#>. Acesso em: 16 Jul. 2014. 